\title{
Recent Development in Finite Element Methods and Computer Aided Design in the Development of Porous Scaffolds-A Review
}

\author{
Nitin Sahai ${ }^{1 *}$ and Tewari RP ${ }^{2}$
}

${ }^{1}$ Lovely Professional University, Jalandhar, India

${ }^{2}$ Motilal Nehru National Institute of Technology, Allahabad, India

\begin{abstract}
Tissue engineering the development of functional substitute to replace missing or malfunctioning human tissue and organs by using biodegradable biomaterials as scaffolds to direct specific cell types to organize into three dimensional structures and perform differentiated function of targeted tissue. The important factors to be considered in designing of microstructure were porosity, pore size, and pore structure with respect to nutrient supply for transplanted and regenerated cells. Performance of various functions of the tissue structure depends on porous scaffold microstructures with specific porosity, pore size, characteristics that influence the behavior of the incorporated cells. Finite element Methods (FEM) and Computer Aided Design (CAD) combines with manufacturing technologies such as Solid Freeform Fabrication (SFF) helpful to allow virtual design, characterization and production of porous scaffold optimized for tissue replacement with appropriate pore size. Finite Element Modeling used to calculate the stress areas in a complex scaffold structures and thus predict their mechanical behavior during in vivo environment (eg. As load bearing in bone tissue scaffolds) is evaluated. This article reviews recent development and application of Finite Element Methods (FEM) and Computer Aided Design and computer-aided manufacturing (CAD \& CAM), and rapid prototyping (RP) technology in the development of porous tissue scaffolds.
\end{abstract}

Keywords: Finite element methods; Computer aided design; Tissue engineering

\section{Introduction}

Tissue scaffold are the synthetic bioresorbable polymers that are functional substitutes to replace missing or malfunctioning human tissues and organ, to provide a temporary substrate to which the transplanted cells can adhere is the primary role of a scaffold.

The important factors to be considered with respect to nutrient supply to transplanted and regenerated cells are porosity, pore size and pore structure for porous scaffolds with a large surface-area-to volume ratio and a large void volume are desirable for attachment, growth, maximal cell seeding, ECM production, and vascularization. Pores in scaffolds of same diameter are preferable to yield high surface area per volume provided the pore size is greater then the diameter of a cell in suspension [1].

Experiments have demonstrated optimal pore size of $20 \mu \mathrm{m}$ for adult mammalian skin regeneration, and $200-400 \mu \mathrm{m}$ for bone in growth $[2,3]$. The rate of tissue invasion into porous scaffolds also depends on the pore size and polymer crystallinity [4-6]. For the architect and fabrication of tissue scaffolds of exact pore size \& porosity as that is required for the growth of tissue cell in scaffold were obtained with the help of computer aided design \& computer aided manufacturing (CAD \& CAM) and finite element method (FEM). The utilization of computer-aided technologies in tissue engineering has evolved in the development of a new emerging field of computer-aided tissue engineering (CATE). CATE comprises of computer imaging technology, CAD/CAM and modern design and manufacturing technology. The classification of CATE is done in three major categories (1) computer-aided tissue anatomical modeling; (2) computer-aided tissue classification; and (3) computer-aided tissue implantation [7].

On the other hand if the mechanical properties of material of tissue scaffolds are known then with the help of Finite Element Modeling (FEM) we are able to predict the behavior of complex structures, such as multilayer system [8-14]. When tissue scaffold is in vivo condition then there will be some microscopic loads(compressive loads and fluid flow) as the tissue differentiation proceeds, it is difficult to determine the local mechanical stimuli sensed by the cells at a microscopic level, for the study of stress strain relationship at microscopic level Finite Element Analysis is used. Finite element analysis (FEA) and Computer Aided Design (CAD) combines with manufacturing technologies such as Solid Freeform Fabrication (SFF) helpful to allow virtual design, characterization and production of scaffold optimized for tissue replacement, make possible to design and manufacture very complex tissue scaffold structure with functional components that are difficult to fabricate. This paper presents a review on the recent development in CAD/CAM \& FEM for the fabrication of porous scaffolds and how the porosity can be effectively represented and modeled.

\section{Scaffold modeling through computed tomographic images}

Computer Tomographic (CT) Images and Magnetic resonance Images (MRI) are used for the generation of $2 \mathrm{D}$ anatomical view of sample and with the help of that series of 2-D images 3-D anatomical view of an object will be created and which can be used for SFF. The anatomical model of human tissue is generated with the help of noninvasive imaging technique, such as CT or MRI technology. Each CT image actually computed of tiny picture element (pixels) which turns in to a small volume element (voxel) of patient tissue sampled by the CT scanner [15].

*Corresponding author: Nitin Sahai, Assistant Professor, Lovely Professional University, Jalandhar, India, E-mail: nitinbiotech@gmail.com

Received September 16, 2011; Accepted January 16, 2012; Published January 18,2012

Citation: Sahai N, Tewari RP (2012) Recent Development in Finite Element Methods and Computer Aided Design in the Development of Porous Scaffolds-A Review. J Tissue Sci Eng 3:113. doi:10.4172/2157-7552.1000113

Copyright: () 2012 Sahai N, et al. This is an open-access article distributed under the terms of the Creative Commons Attribution License, which permits unrestricted use, distribution, and reproduction in any medium, provided the original author and source are credited. 
CT images is not ethically justified because of dose of radiation administrated on the other hand MRI is consider to be better than CT images as its ability to show subtle differences in soft tissue anatomy without the harmful effects of ionizing radiation present in CT. Table 1 give a comparison of imaging characteristic commonly used in production of 3-D reconstruction CT and MRI [15], the use of nondestructive characterization techniques such as micro-computed tomography (micro CT) is used for the three-dimensional scaffolds with an internal pore structure[16]. Micro CT is a more recent nondestructive method of examining the characteristics of scaffolds [17] as well as in the modeling and fabrication of scaffolds. In vivo micro CT scanning has been shown to be both repeatable and reproducible [18]. Micro CT is a useful tool both for studying the location and extent of growth into a polymeric scaffold, and for determining whether the regenerated tissue has blood supply [19].

Three-Dimensional reconstruction techniques help in the development of 3-D anatomical model or images and allow the third dimension to be studied directly by displaying of 3-D anatomical image [7]. Although voxel based anatomical representation through CT/MRI images cannot be effectively used in many biomechanical engineering activities such as anatomical structural design, modeling-based anatomical design modeling-based anatomical tissue biomechanical analysis and simulation [20-22]. CAD system and CAD- based solid modeling which is based on vector modeling environment is used for anatomical modeling design, analysis and simulation.

\section{CAD in tissue engineering}

CAD system use the 'Boundary Representation' (B-REP) in which a solid object is defined by the surface which bound to it and thes surfaces are describes with the help of non-uniform rational B-spline (NURBS) functions [23-25]. CAD contributes to the shortening the design process of scaffolds and also contributes to the minimizing of experimental tests [26,7]. Since 2000, chemical based techniques for fabrication of scaffolds made way to alternate methods of fabrication that had the capability to be integrated with CAD/CAM technologies [27-29]. This made it possible for the scaffolds to be designed using CAD software and then transferred for rapid protyping for its fabrication. To bridge the gap between medical imaging and CAD design software a standard module Med CAD is used. Med CAD interface can export the data from the CT/MRI system to CAD platform and vice versa through either IGES (International Graphics Exchange Standard), STEPS (Standard for Exchange of Product) or STL format. Med CAD interface is software of imaging. It is helpful in exporting the data from the imaging system to CAD and also from IGES (International Graphics Exchange Standard), STEP (Standard for Exchange of Product) or STL format. The interface of Med CAD provides for the fitting of primitives such as cylinder, spheres, planes etc. at the Imaging 2-D segmentation slices and also provides the limited ability to model B-Spline surfaces. B-splines are known to represent the freeform objects closely. The B-spline tensor product modeling methodology is presented in this paper to model both geometry and material variation

\begin{tabular}{|c|c|c|}
\hline Characteristics & CT & MRI \\
\hline Matrix size(Pixel) & $512 \times 512$ & $256 \times 256$ \\
\hline Voxel size $(\mathrm{mm})$ & $0.5 \times 0.5 \times 2.0$ & $0.5 \times 0.5 \times 1.5$ (gap) \\
\hline Density resolution & 4096 levels $(12$ bit) & 128 levels $(16$ bit) \\
\hline Signal to noise ratio & High & Moderate \\
\hline Segmentation & Threshold & Complex \\
\hline Porotocol & Simple (radiation) & Complex (benign) \\
\hline
\end{tabular}

Table 1: Characteristics comparison of CT and MRI. of human body slice from CT scan image. As B-splines are known to represent the freeform objects closely, it is proposed to represent both, the geometry and the density with B-splines [30]. The limitation of Med CAD interface is the incapability to capture details and complex tissue anatomical features, particularly for features with complex geometry [26] Figure 1.

W. Sun et al. [26] had evaluated and compared following three different process paths for generating a CAD model from medical imaging data: (1) MedCAD interface approach, (2) reverse engineering interface approach, and (3) STL triangulated model converting approach. The outline of the processes is presented in Figure 2.

The micro-architecture of tissue scaffold is believed to influence the biological function of tissues and behavior of cells by providing spatial distribution for cell growth and providing a nutritional pathway and proliferation to cells. The problem in the fabrication of scaffolds are often limited in practicle thickness due in part, to the difficulty in getting cells deep into interior regions of scaffold then this problem is eliminated with the help of adopting an advance technology for the synthesis of scaffolds such as Solid Free Form Fabrication(SFF) [31-34]. As the advancement takes place in the SFF it become the most favorable approach in the fabrication of scaffold, the interior architecture of these scaffolds were either designed as a pattern of extrusions, cuts and holes across the surface of the tissue scaffolds in a CAD platform.

\section{CAD for Porous tissue scaffolds}

In scaffold the porosity and pore size will play a critical role in tissue and cell formation in vitro and in vivo. The density and structure of many manufactured components could be designed to achieve optimum performance if the local porosity of formed material could be controlled [35]. Studies had shown that both mechanical and biological properties of porous scaffolds, cell growth and migration processes are determined in part by the local micro architecture of tissue scaffolds. For example, specific pore size and overall porosity of the scaffold are favorable to specific cells which affect their cellular adhesion, ingrowth, distribution, viability, and the formation of an extra cellular matrix [36,37]. Image based design (IBD) method is develop previously for the external scaffold shape and global porous architecture [38] The internal architectures of porous tissue scaffolds determine the mechanical properties of the scaffolds and control degree of tissue regeneration [39-41].

To build designer tissue-engineering scaffolds Scott j Hollister [42] reviewed the integration of of computational topology design (CTD) with the solid free-form fabrication. Pallavi Lal and Wei Sun [43] proposed a computer modeling approach for constructing 3-dimensional microsphere-packed bone graft structure which consist two extreme microsphere-packing models(minimum \& maximum density packing). Chua CK et al. [44,45] for tissue engineering proposed a novel modeling approach. Various polyhedral shapes as a unit cell for bone scaffold modeling are selected. In the tissue engineering bone scaffold modeling to assists the users in the application of CAD modeling, a standard parametric library of scaffold structure were designed and developed from which a user could select cell unit and size as suit to it. A library of CAD based unit cell of scaffolds is generated derived from different feature primitive patterns is presented in Figure 3 [26]. As an open polyhedral cell unit was finalized and sized then an automatic algorithm for generating complex polyhedral scaffolds [46] was employed to assemble the micro architecture of the scaffold. Craig Schroeder and Wei Sun [47] noticed the differences between the bone scaffolds fabricated by rapid prototyping technology 


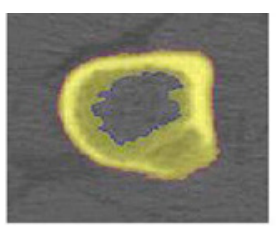

(a) Polylines contours used to dem arcate boundary regions

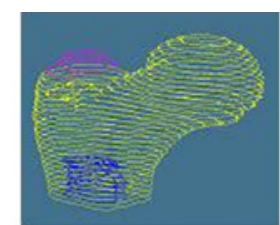

(b) Polylines were grown through the segmented images

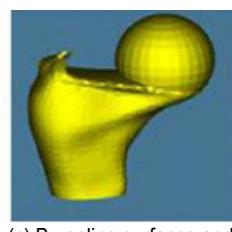
primitives (sphere) used
Figure 1: CAD model construction using MedCAD interface [26].

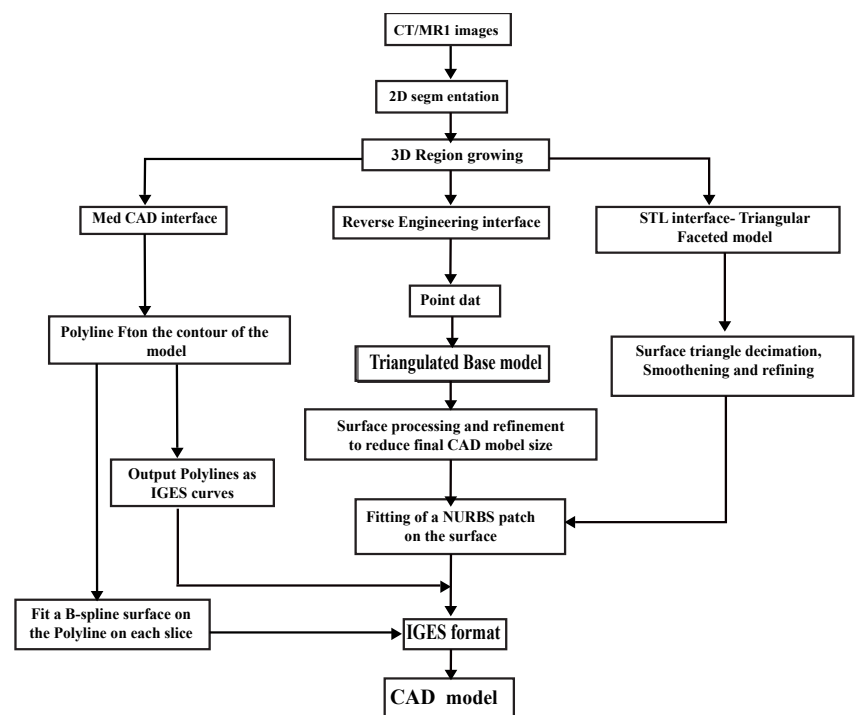

Figure 2: Process definition to arrive at a CAD model from CT/MRI data [26].
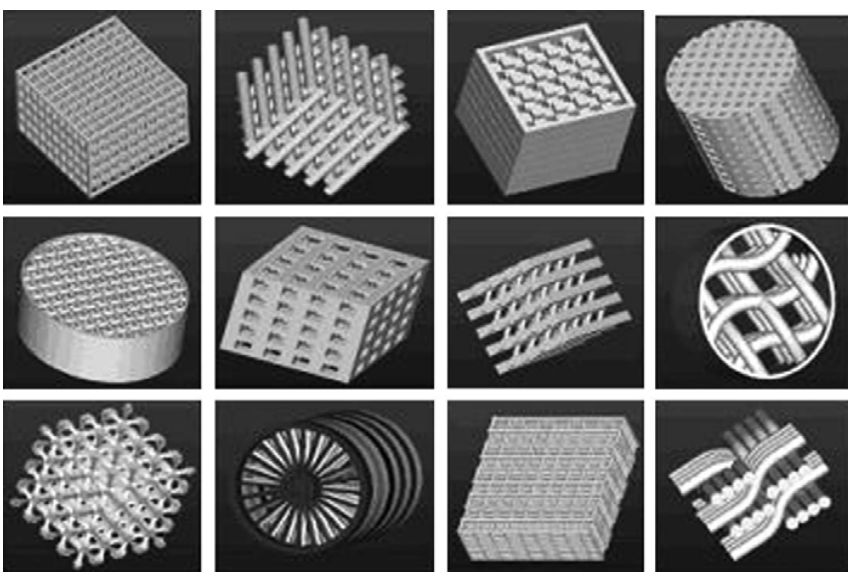

Figure 3: A library of designed scaffold unit cells based on different feature primitives. Adapted from W Sun et al. [26].

and natural structures from SEM (Scanning Electron Microscope) images by generating a stochastic model for a Berea sandstone and a Fontainebleau sandstone, with each a prescribed lineal-path function, two-point probability function and "pore-size" distribution function. The pore distribution and pore size were controlled based on the stochastic geometry theory and minimum distance between pores.

Jie Li and Wei Sun [48] use a swept volume representation methods for the fabrication of tissue scaffolds which described the tool path information and generate a virtual scaffold prototyping. Wettergreen MA et al. [49] created a library of unit cell of the tissue scaffold architectures that could be beneficial to collection a complex tissue scaffold of individual, well characterized microstructure. Shengyon Cai and Juntong Xi [50] has given a control modeling approach for constructing tissue engineering bone scaffold with defined pore size distribution based on the hexahedral mesh refinement which enjoyed easy controllability and higher accuracy in comparison to other methods such as varying processing parameter in supercritical fluid processing and multi-interior architecture design. Ravi $\mathrm{M}$ et al. [51] presented two different types of modeling methods which is capable of representing both the soft and the hard tissue, namely B-spline heterogeneous fairing and B-spline heterogeneous fit. These two approaches will give the use modeling flexibility when used with different proportion of CT data Figure 3 .

\section{Finite Element Methods in Tissue Engineering}

As the development of the tissue will takes place in scaffolds then there is an increase of cell differentiation and extracellular matrix synthesis will takes which will cause the increase in compressive load, and fluid flow with high velocity which is associated with cell apoptosis and finally when they are combined with each other then they will show to increase the extracellular matrix synthesis. It is very clear that there is a direct relationship between the tissue differentiation and macroscopic mechanical loads (compressive loads \& fluid flow). Now it will become a difficult task to determine the local mechanical stimuli which is sensed by the cell at microscopic level then strain and stress distribution on a scaffolds at microscopic level can be studied by using Finite Element Method (FEM) which is helpful in development and fabrication of scaffold of exact mechanical strength that is required in the development phase of tissue in scaffolds. If the mechanical properties of the materials comprising the structure are known then FEM has shown to be capable of predicting the behavior of complex structures such as multilayer system [52-55].

Miranda P et al. [56] used Finite Element Method(FEM) as a tool to calculate the stress fields in complex tissue scaffold structures and thus predict their mechanical behavior during their service(eg as load bearing bone implants) is evaluated. This method is applied for identifying the facture modes and estimating the strength of robocast tissue scaffold. The calculation is performed for three testing configuration: Compression, Tension, and Shear. The tools applied for FEM are ANSYS, MSC Nastran and MSC Patran etc. Finite element Modeling Fang $\mathrm{Z}$ et al. [57] done the computer aided characterization approach to evaluate the effective mechanical properties of porous scaffold. The computational algorithm that is applied in characterization is finite element implementation of asymptotic homogenization theory. The characterization results of PCL shows that its effective mechanical properties are the function of scaffolding materials and overall porosity of scaffold structure. Lacroix et al. [58] did finite element analysis of cylinders of CaP-based scaffolds to calculate the stress-strain distribution throughout larger scaffolds.

To calculate the mechanical properties of microstructure multiscale fine element models using the homogenization theory have been used [59]. Andy L. Olivares et al. [60] modeled the gyroid and hexagonal scaffold of $55 \%$ and $77 \%$ porosity in a finite element analysis and were submitted to an inlet fluid flow or compressive strain and results shows that gyroid architecture provides a better accessibility of the fluid then the hexagonal structure. This shows that the distribution of the shear stress induced by fluid perfusion is very dependent on pore distribution 
with in the scaffolds. Zaoyang Guo et al. [61] proposed a FEM-based direct method material reconstruction inverse problem in soft tissue elastography. The results can be obtained by minimizing he objective function, defined as the sum of the square of the residual norms at all nodes where the nodal residual norm of the associated elements is defined as a linear function of elasticity parameters. By satisfying the equilibrium at every node is utilized as the optimization objective and the measured deformation is enforced directly as a result, the soft tissue elastography can be obtained directly by solving the resulting set of linear equations and no iterations are required.

Sandino C et al. [62] uses micro computed tomographed (CT)based finite element (FE) models of the real shape of the solid material phase and the pores provides detailed information about mechanical stimuli caused by mechanical loading on the extracellular matrix and interstitial fluid flow within the internal walls of two biomaterial scaffolds with different morphologies.Two samples of porous materials, one of calcium phosphate-based cement and another of biodegradable glass, were used. Elbert Baas et al. [63] shows that by using linear microfinite element $(\mu \mathrm{FE})$ technique based on micro-computed tomography $(\mu \mathrm{CT})$ the local displacements at a microscopic level in sizable polymer scaffolds can be calculated.

\section{Conclusion}

From the above literature review computer aided tissue engineering and finite element methods combines with the rapid protyping technology helps in development of the exact microstructure of tissue scaffold as needed for the proper growth of tissue and organ. With the establishment CATE we can get more accurate and more realistic models that can simulate the biological process and the design of biomaterial scaffolds.

\section{References}

1. Ratner, Antonios G, Mikos 8.4 synthetic bioresorbable polymer scaffolds. 735749 .

2. Boyan BD, Hummert TW, Dean DD, Schwartz Z (1996) Role of material surfaces in regulating bone and cartilage cell response. Biomaterials 17: 137146.

3. Whang K, Thomas $\mathrm{CH}$, Healy KE, Nuber G (1995) A novel method to fabricate bioadsorbable scaffolds. Polymer 36: 837-842.

4. Mikos AG, Sarakinos G, Lyman MD, Ingber DE, Vacanti JP, et al. (1993) Prevascularization of porous biodegradable polymers. Biotechnol Bioeng 42: 716-723.

5. Park A, Cima LG (1996) In vitro cell response to differences in poly-L-lactide crystalinity. J Biomed Mater Res 31: 117-130.

6. Wake MC, Patrick CW Jr, Mikos AG (1994) Pore morphology effects on fibrovascular tissue growth in porous polymer substrates. Cell Transplant 3 : 339-343.

7. Sun W, Lal P (2002) Recent development on computer aided tissue engineeringa review. Comput Methods Programs Biomed 67: 85-103.

8. Zhao $\mathrm{H}$, Miranda $\mathrm{P}$, Lawn BR, Hu XZ (2002) Cracking in ceramic/metal/ polymer trilayer systems. J Mater Res 17: 1102-1111.

9. Chai H, Lawn BR (2002) Cracking in brittle laminates from concentrated loads. Acta Materialia 50: 2613-2625.

10. Miranda P, Pajares A, Guiberteau F, Deng Y, Lawn BR (2003) Designing damage-resistant brittle-coating structures: I Bilayers. Acta Materialia 51: 4347 4356 .

11. Miranda P, Pajares A, Guiberteau F, Deng Y, Zhao H, et al. (2003) Designing damage-resistant brittle-coating structures: II. Trilayers. Acta Materialia 51: 4357-4365.

12. Hsueh CH, Luttrell CR, Becher PF (2006) Analyses of multilayered dental ceramics subjected to biaxial flexure tests. Dent Mater 22: 460-469.
13. Kim JH, Miranda P, Kim DK, Lawn BR (2003) Effect of an adhesive interlaye on the fracture of a brittle coating on a supporting substrate. J Mater Res 18 222-227.

14. Deng Y, Miranda P, Pajares A, Guiberteau F, Lawn BR (2003) Fracture of ceramic/ceramic/polymer trilayers for biomechanical applications. J Biomed Mater Res A 67: 828-833.

15. Mankovich NJ, Samson D, Pratt W, Lew D, Beumer J 3rd (1994) Surgica planning using three-dimensional imaging and computer modeling. Otolaryngo Clin North Am 27: 875-889.

16. Ho ST, Hutmacher DW (2006) A comparison of micro CT with other techniques used in the characterization of scaffolds. Biomaterials 27: 1362-1376.

17. Saey Tuan Ho, Dietmar W, Hutmacher (2006) A comparison of micro CT with other techniques used in the characterization of scaffolds. Biomaterials 27 1362-1376.

18. Voor M J, Yang S, Burden RL, Waddell SW (2008) In vitro micro-CT scanning of a rabbit distal femur: repeatability and reproducibility. J Biomech 41: 186 193.

19. Watling CP, Lago N, Benmerah S, Fitzgerald JJ, Tarte E, et al. (2010) Nove use of X-ray micro computed tomography to image rat sciatic nerve and integration into scaffold. J Neurosci Methods 188: 39-44.

20. Attawia M, Devin J, Laurencin CT (1995) Immuno fluorescence and confoca laser microscopy studies of osteblast growth and phenotypic expression in three-dimensional degradable synthetic matrices. J Biomed Mater Res 29 : 843-848.

21. Ollivierre F, Gubler U, Towle CA, Laurencin C, Treadwell BV (1986) Expression of IL-1 genes in human and bovine chondrocytes: a mechanism for autocrine control of cartilage matrix degradation, Biochem Biophys Res Commun 141 904-911.

22. Laurencin CT, Morris CD, Pierre-Jacques H, Keaton AR, Schwartz ER, et al. (1992) The development of bone biodegradable polymer composites for skeletal tissue regeneration: studies of initial cell attachment and spread. Polym Adv Tech 359-364.

23. Viceconti M, Zannoni C, Pierotti L (1998) Tri2solid: an application of reverse engineering methods to the cretion of CAD models of bone segments. Comput Methods Program Biomed 56: 211-220.

24. Viceconti M, Casali M, Massari B, Cristofolini L, Bassini S, et al. (1996) The standardized femur program proposal for a reference geometry to be used for the creation of finite element models of the femur. J Biomech 29: 1241.

25. Viceconti M, Zannoni C, Testi D, Capello A (1999) CT data sets surface extraction for biomechanical modeling of long bones. Comput Methods Program Biomed 59: 159-166.

26. Sun W, Starly B, Nam J, Darling A (2005) Bio- CAD modeling and its application in computer-aided tissue engineering. Computer-aided design 37: 1097-1114.

27. Zein I, Hutmacher DW, Tan KC, Teoh SH (2002) Fused deposition modeling of novel scaffold architectures for tissue engineering applications. Biomaterials 23: $1169-1185$

28. Wang F, Shor L, Darling A, Khalil S, Sun W, et al. (2004) Precision Extruding Deposition and Characterization of Cellular Poly-e-Caprolactone Tissue Scaffolds. Rapid Prototyping Journal 10: 42-49.

29. Khalil S, Nam J, Sun W (2005) Multi-nozzle Deposition for Construction of 3D Biopolymer Tissue Scaffolds. Rapid Prototyping Journal 11: 9-17.

30. Bhatt AD, Warkhedkar RM (2008) Reverse Engineering of Human Body: A B-spline based Heterogeneous Modeling Approach. Computer-Aided Design and Applications CAD Solutions, LLC

31. Marra KG, Campbell PG, DiMilla PA, Kumta P, Mooney MP, et al. (1998) Novel three-dimensional biodegradable scaffolds for bone tissue engineering. Mater Res Soc 550: 155-160.

32. Weiss LE, Merz R, Prinz FB, Neplotnik G, Padmanabhan P, et al. (1997) Shape deposition manufacturing of heterogeneous structures. J Manufact Syst 16 : 239-248.

33. Davies JE (1996) In vitro modeling of the bone/implant interface. Anat Rec 245: 426-445.

34. Gomi K, Davies JE (1993) Guided bone tissue elaboration by osteogenic cells in vitro. J Biomed Mater Res 27: 429-431. 
Citation: Sahai N, Tewari RP (2012) Recent Development in Finite Element Methods and Computer Aided Design in the Development of Porous Scaffolds-A Review. J Tissue Sci Eng 3:113. doi:10.4172/2157-7552.1000113

35. Torres-Sanchez C, Corney JR (2008) Effects of ultrasound on polymeric foam porosity. Ultrason Sonochem 15: 408-415

36. Zeltinger J, Sherwood JK, Graham DA, Mueller R, Griffith LG (2001) Effect of pore size and void fraction on cellular adhesion, proliferation, and matrix deposition. Tissue Eng 7:557-572.

37. Nikolovski J, Mooney D (2000) Smooth muscle cell adhesion to tissue engineering scaffolds. Biomaterials 21: 2025-2032.

38. Hollister SJ, LevyRA, Chu TM, Halloran JW, Feinberg SE (2000) An imagebased approach for designing and manufacturing craniofacial scaffolds. Int J Oral Maxillofac Surg 29: 67-71.

39. Le Huec JC, Schaeverbeke T, Clement D, Faber J, Le Rebeller A (1995) Influence of porosity on the mechanical resistance of hydroxyapatite ceramics under compressive stress. Biomaterials 16: 113-118.

40. Magan A, Ripamonti U (1996) Geometry of porous hydroxyapatite implants influences osteogenesis in baboons. J Craniofac Surg 71-78.

41. Chang BS, Lee CK, Hong KS, Youn HJ, Ryu HS, et al. (2000) Osteoconduction at porous hydroxyapatite with various pore configurations. Biomaterials 21 : 1291-1298.

42. Hollister Scott J (2005) Porous scaffold design for tissue engineering. Nat Mater 4: 518-524.

43. Pallavi Lal, Wei Sun (2004) Computer modeling approach for microspherepacked bone scaffold. Computer-Aided Design 36: 487-497.

44. Chua CK, Leong KF, Cheah CM, Chua SW (2003) Development of a Tissue Engineering scaffold structure library for rapid prototyping. Part 1: Investigation and classification. Inter J Adv Manu Tech 21: 291-301.

45. Chua CK, Leong KF, Cheah CM, Chua SW (2003) Development of a Tissue Engineering scaffold structure library for rapid prototyping. Part 2: Parametric library and assembly program. Inter J Adv Manu Tech 21: 302-312.

46. Cheah CM, Chua CK, Leong KF (2004) Automatic algorithm for generating complex polyhedral scaffolds for tissue engineering. Tissue Eng 10: 595-610.

47. Schroeder C, Regli William CR, Ali S, Sun W (2005) Computer-aided design of porous artifacts. Computer-Aided Design 37: 339-353.

48. Li J, Regli W, Sun W (2005) A case study of swept volume representation of tissue scaffolds. Bioengineering Conference Proceedings of the IEEE 31st annual northeast 182-183.

49. Wettergreen MA, Bucklen BS, Starly B, Yuksel E, Sun W, et al. (2005) Creation of a unit block library of architectures for use in assembled scaffold engineering. Computer-Aided Design 37: 1141-1149.
50. Cai S, Xi J (2008) A control approach for pore size distribution in the bone scaffold based on the hexahedral mesh refinement. Computer-Aided Design 40: 1040-1050.

51. Warkhedkar RM, Bhat AD (2009) Material- solid modeling of human body: A heterogeneous B-spline based approach. Computer -Aided Design 41: 586 597

52. Karageorgiou V, Kaplan D (2005) Porosity of 3D biomaterial scaffolds and osteogenesis. Biomaterials 26: 5474-5491.

53. Miranda P, Pajares A, Saiz E, Tomsia AP, Guiberteau F (2008) Mechanical properties of calcium phosphate scaffolds fabricated by robocasting. J Biomed Mater Res A 85: 218-227.

54. Adachi T, Osako Y, Tanaka M, Hojo M, Hollister SJ (2006) Framework for optimal design of porous scaffold microstructure by computational simulation of bone regeneration. Biomaterials 27: 3964-3972.

55. Miranda P, Pajares A, Guiberteau F, Deng Y, Lawn BR (2003) Designing damage-resistant brittle-coating structures: I. Bilayers. Acta Mater 51: 43474356.

56. Miranda P, Pajares A, Guiberteau F (2008) Finite element modeling as a too for predicting the fracture behavior of robocast scaffolds. Acta Biomater 4 1715-1724.

57. Fang Z, Straly B, Sun W (2005) Computer-aided characterization for effective mechanical properties of porous tissue scaffolds. Computer-Aided Design 37: 65-72.

58. Lacroix D, Chateau A, Ginebra MP, Planell A (2006) Micro-finite elemen methods of bone tissue-engineering scaffolds. Biomaterials 27: 5326-5334.

59. Hollister SJ, Maddox RD, Taboas JM (2002) Optimal design and fabrication of scaffolds to mimic tissue properties and satisfy biological constraints. Biomaterials 23: 4095-4103.

60. Olivares AL, Marsal E, Planell JA, Lacroix D (2009) Finite element study of scaffold architectie design and culture conditions for tissue engineering Biomaterials 30: 6142-6149.

61. Guo Z, You S, Wan X, Bićanić N (2010) A FEM-based direct method fo material reconstruction inverse problem in soft tissue elastography. Computers \& Structures 88: 1459-1468.

62. Sandino C, Planell JA, Lacroix D (2008) A finite element study of mechanica stimuli in scaffolds for bone tissue engineering. J Biomech 41: 1005-1014.

63. Baas E, Kuiper JH (2008) A numerical model of heterogeneous surface strains in polymer scaffolds. J Biomech 41: 1374-1378. 